Correction

\title{
Wang L.K., et al. Two New Lanostane Triterpenoids from the Branches and Leaves of Polyalthia oblique. Molecules 2014, 19, 7621-7628
}

\author{
Liu-Kai Wang ${ }^{\dagger}$, Cai-Juan Zheng ${ }^{\dagger}$, Xiao-Bao Li, Guang-Ying Chen, Chang-Ri Han, Wen-Hao Chen \\ and Xiao-Ping Song *
}

Received: 29 October 2015 ; Accepted: 2 November 2015 ; Published: 11 November 2015

Academic Editor: Derek J. McPhee

Key Laboratory of Tropical Medicinal Plant Chemistry of Ministry of Education,

College of Chemistry and Chemical Engineering, Hainan Normal University, Haikou 571158, Hainan, China

* Correspondence: sxp628@126.com; Tel./Fax: +86-898-6588-4995

$\dagger \quad$ These authors contributed equally to this work.

The authors wish to make the following correction to their paper [1], published recently in Molecules. The names of compounds $\mathbf{1}$ and $\mathbf{2}$ were not correct, and there were some minor errors in the chemical structure of compound 3 shown in Figure 1 of this paper [1]. The names of compounds 1 and 2 should be changed to $(3 \beta, 20 \beta)$-3,20-dihydroxy-24-methylenelanost-8-ene-7-one (1) and $(3 \beta, 15 \alpha)$-3,15-dihydroxy-24-methylenelanost-8-ene-7,11-dione (2). The corrected structure of 3 is shown in Figure 1.

The manuscript will be updated and the original will remain online on the article webpage.

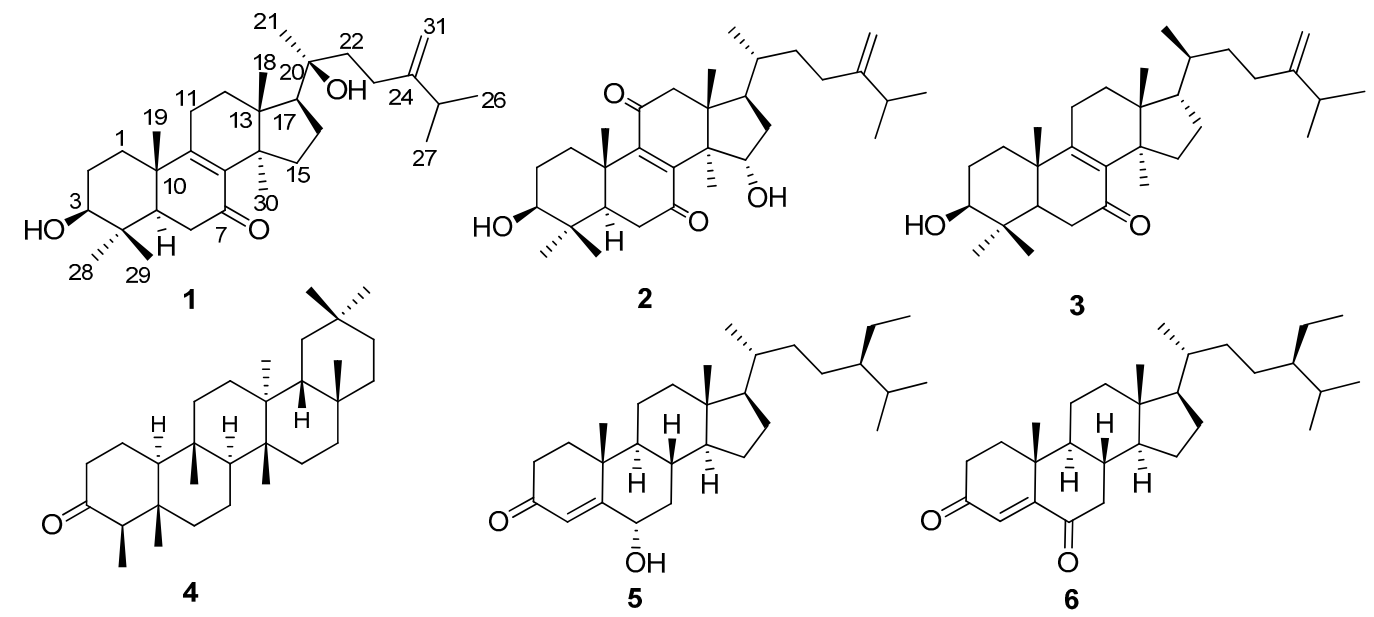

Figure 1. Structures of compounds 1-6.

\section{Reference}

1. Wang, L.K.; Zheng, C.J.; Li, X.B.; Chen, G.Y.; Han, C.R.; Chen, W.H.; Song, X.P. Two new lanostane triterpenoids from the branches and leaves of Polyalthia oblique. Molecules 2014, 19, 7621-7628. [CrossRef] [PubMed]

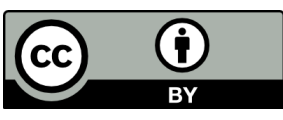

(C) 2015 by the authors; licensee MDPI, Basel, Switzerland. This article is an open access article distributed under the terms and conditions of the Creative Commons by Attribution (CC-BY) license (http://creativecommons.org/licenses/by/4.0/). 